\title{
Llibres i revistes rebuts
}

\section{Llibres}

BERMEJO, Diego (2008). En las fronteras de la ciencia. Barcelona: Anthropos.

CAssigoli, Rossana (2008). Pensar lo femenino: Un itinerario filosófico hacia la alteridad. Barcelona: Anthropos.

GALINDO, Jorge (2008). Entre la necesidad y la contingencia: Autoobservación teórica de la sociología. Barcelona: Anthropos.

García CalaVia, Miguel Ángel (2008). Sociologia de les relacions laborals. PUV.

GARCÍA-PAGE SÁNCHEZ, Mario (2008). Introducción a la fraseología española: Estudio de las locuciones. Barcelona: Anthropos.

GONZÁLEZ AlCANTUD, José A. (2008). La ciudad magrebi en tiempos coloniales: Invención, conquista y transformación. Barcelona: Anthropos.

HALBWACHS, Maurice (2008). La memoria colectiva, una categoría innovadora de la sociología actual. Barcelona: Anthropos.

Muntané, M. D. (2008). Antienvejecimiento, longevidad, salud y felicidad. Barcelona: Anthropos.

Pérez QueVedo SaAvedra Fajardo, Antonio y otros (2008). El arte de gobernar: Antología de textos filosóficos-politicos. Siglos XVI-XVII. Barcelona: Anthropos.

Platero, Raquel (2008). Lesbianas. Discursos y representaciones. Barcelona: Melusina.

Rodríguez, Ielana; MARTíneZ, Josebe (2008). Postcolonialidades históricas: (in) visibilidades hispanoamericanas/colonialismos ibéricos. Barcelona: Anthropos.

TRAPASSI, Leonarda; MARTOS RAMOS, José Javier (2008). Recursos de la mentira: lenguajes y textos. Barcelona: Anthropos.

VATtimo, Gianni (2008). Hermeneusis e historicidad. Barcelona: Anthropos.

WIENER, Gabriela (2008). Sexografias. Barcelona: Melusina.

\section{Revistes}

Cuadernos de Relaciones Laborales, 2008, vol. 26, núm. 1, MiguÉLEZ, Fausto (ed.). "Globalización y sindicalismo».

Íconos. Revista de Ciencias Sociales, núm. 31. Equador, maig de 2008, "Los retos del pluralismo jurídico».

Quaderns Gadeso: Anàlisi de la realitat socioeconòmica de les Illes Balears, núm. 122, 2008. 
Quaderns Gadeso: Anàlisi de la realitat socioeconòmica de les Illes Balears, núm. 125, 2008.

Revista d'Administración Pública, núm. 176. Madrid, maig-agost de 2008.

Revista Española de Investigaciones Sociológicas. Centro de Investigaciones Sociológicas, juliol-setembre de 2008.

Revista Internacional de Pensamiento Político, núm. 2, primer semestre de 200, «Naciones y nacionalismos en España».

Theoria. Revista de teoria, historia y fundamentos de la ciencia, núm. 60. 